\title{
Influence of Compression Pressure and Velocity on Tablet Sticking
}

\author{
Kazuyuki KaKimi, * Toshiyuki Niwa, and Kazumi Danjo \\ Faculty of Pharmacy, Meijo University; 150 Yagotoyama, Tempaku-ku, Nagoya 468-8503, Japan. \\ Received January 21, 2010; accepted September 21, 2010; published online September 27, 2010
}

\begin{abstract}
A rotary tablet machine fitted with 8-mm diameter flat-faced punches was used to measure scraper pressure (SCR), a type of shear stress, to evaluate sticking behavior. The shear stress between the surfaces of the tablet and lower punch was determined using an SCR detection system. Mean surface roughness $\left(R_{\mathrm{a}}\right)$ of tablets, measured by a scanning laser-microscope, was used to estimate the magnitude of sticking. Tablet tensile strength tended to increase with compression pressure at either of the tablet production velocities tested, which was consistent with previous reports. SCR decreased with increasing compression pressure for samples at all compression velocities, and showed a tendency to increase with binder concentration. SCR also tended to increase with compression velocity for samples at all compression pressures, suggesting that the frequency of tablet sticking increased as compression velocity increased. $R_{\mathrm{a}}$ associated with sticking increased with SCR, indicating that the adhesive force between the particles of the tablet surface and the lower punch surface plays an important role in sticking.
\end{abstract}

Key words scraper pressure; surface roughness; adhesive force; compression pressure; compression velocity

Sticking and picking are problems encountered during the manufacturing of tablets and are obstacles to producing high-quality tablets. These problems are generally attributed to adhesion between the compressed particles of the tablet surface and the surface of the punch, the potential causes of which include sticking and picking events, which can be categorized as follows: 1) Physicochemical factors of the compressed materials, such as melting point, particle size and distribution, surface condition, and particle hardness. 2) Mechanical factors, such as surface conditions of the punch, compression force, and velocity. 3) Environmental factors, such as the temperature and humidity around the machine. ${ }^{1)}$

Schmidt $e t$ al. $^{2)}$ measured the force required to remove a tablet from a punch surface. Naito et al. ${ }^{3-5)}$ reported a method for measuring the slipping force of a tablet surface and the passive pressure of the lower punch during compression. Toyoshima et al. $\left.{ }^{6}\right)$ suggested that the surface roughness $\left(R_{\mathrm{a}}\right)$ of the compacts could be an effective parameter for predicting sticking. Sugimori et $a l^{7)}$ reported that capping occurs when a tablet is cracked by high residual die wall pressure at the final stage of the decompression process. However, no real-time methodology has been developed to assess sticking and picking during tableting operations. Recently, Sawaguchi et al $^{8)}$ reported that tablet sticking is reduced by applying electron beam processing infinite product technology to the punch used for tableting.

Measurement of scraper pressure (SCR), which is a parameter used to evaluate shear stress ${ }^{9)}$ during desorption of the compact from the surface of the lower punch, should therefore be the most direct means of evaluating sticking and picking.

The purpose of the present study was therefore to quantify sticking and picking characteristics based on SCR values. The effects of compression pressure and compression velocity on the incidence of sticking during compression were examined because sticking is commonly associated with a decrease in compression pressure and an increase in compression velocity. Measurements were carried out under a variety of compression pressure and compression velocity conditions, and the results were clarified on the basis of these factors.

\section{Experimental}

Materials $n$-Butyl $p$-hydroxybenzoate (BHB) (Kanto Kagaku Co., Ltd., Japan) was passed through a $125 \mu \mathrm{m}$ air-jet sieve (Alpine Hosokawa AG Co., Ltd., Japan). Lactose was obtained from DMV (JP15 grade, 200 meshes, DMV-Fonterra Excipients DmbH, Germany). Light anhydrous silicic acid (Aerosil 200) was purchased from Japan Aerosil Co., Ltd., Japan. Hydroxypropylcellulose (HPC-SL) was acquired from Nippon Soda Co., Ltd., Japan. Magnesium stearate was purchased from Yoneyama Chemical Industry, Japan.

Methods. Measurement of Melting Point Melting point was measured by differential scanning calorimetry (DSC) (DSC60, Shimadzu, Japan), with a modulated temperature setting of $10^{\circ} \mathrm{C} / \mathrm{min}$ from 30 to $150^{\circ} \mathrm{C}$.

Granulation Method $n$-Butyl $p$-hydroxybenzoate, lactose, aerosil and HPC-SL aqueous binding solution $(80-85 \mathrm{ml} ; 3,5,7 \mathrm{w} / \mathrm{v} \%)$ as shown in Table 1 were kneaded in a kneading machine (AR-400, Erweka GmbH, Germany) for $18 \mathrm{~min}$ before being granulated using an extruder (KAR-300, Tsutsui Rikagakukikai, Co., Ltd., Japan) with a $1.0 \mathrm{~mm}$ sieve opening and then dried at the room temperature for $24 \mathrm{~h}$.

After drying, the granules were separated using a sieving machine set to $710-1180 \mu \mathrm{m}$ and $0.1 \%$ of magnesium stearate was added to $500 \mathrm{~g}$ of the granules which were then mixed using a V-type mixer (Fuji Paudal, Co., Ltd., Japan) for $15 \mathrm{~min}$.

Tableting Six flat faced punches of the $8 \mathrm{~mm}$ diameter were set in the rotary machine (Cleanpress Correct 12 Huk-Aw, Kikusui Seisakusho Ltd., Japan), and tablets were prepared by the compression pressures of 98, 146, and $195 \mathrm{MPa}$. The weight of a tablet was adjusted to be $200 \pm 10 \mathrm{mg}$ and the velocity of the rotary table during tableting was tested at 10,15 , and $20 \mathrm{rpm}$.

Measurement of SCR A rotary tablet machine (Correct 12 Huk-Aw, Kikusui Seisakusho Ltd., Kyoto, Japan) fitted with one set of six $8 \mathrm{~mm}$ diameter flat-faced punches was used to measure SCR during 5-10 revolutions of the rotary table. Shear stress between the tablet and the lower punch surface was measured using an SCR detection system ${ }^{1)}$ placed on the scraper. The output strain value was analyzed using a compression stress analyzer (Daatsu, Okada Seiko Co., Ltd., Japan).

Measurement of Surface Roughness $R_{\mathrm{a}}(\mu \mathrm{m})$, a measure of surface unevenness, was measured by scanning laser microscopy at a magnification

Table 1. Formulation of Granules

\begin{tabular}{lr}
\hline \hline \multicolumn{1}{c}{ Material } & \multicolumn{1}{c}{ Weight } \\
\hline$n$-Butyl $p$-hydroxybenzoate & $200 \mathrm{~g}$ \\
Lactose 200 & $390 \mathrm{~g}$ \\
Aerosil 200 & $10 \mathrm{~g}$ \\
Solution of 3\%, 5\%, 7\% HPC-SL & $80-85 \mathrm{ml}$ \\
\hline
\end{tabular}




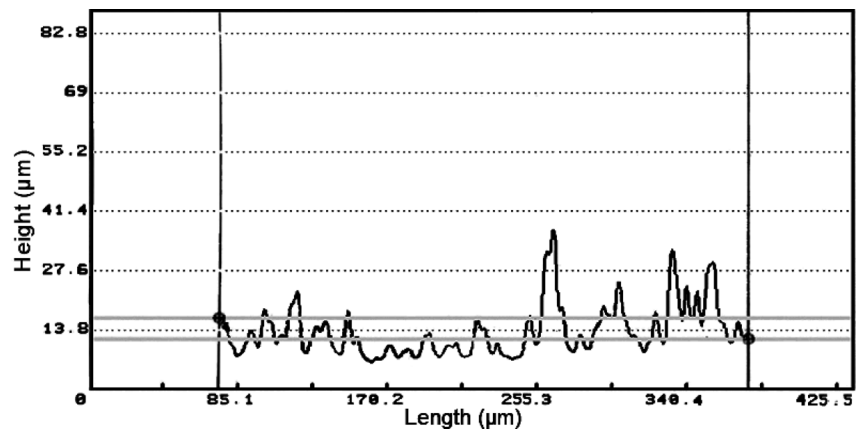

Fig. 1. Chart of Tablet Surface Roughness Obtained by Scanning Laser Microscopy

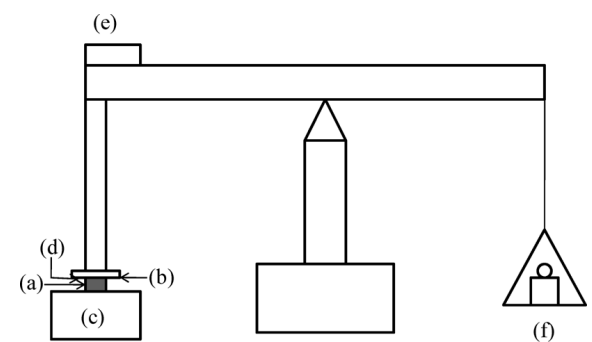

Fig. 2. Schematic Diagram of Equipment Used for Adhesive Force Measurements

(a) Tablet; (b) aluminum plate; (c) metal plate; (d) double-sided adhesive tape; (e) weight; (f) balance.

of $\times 20$ (1LM21, Laser Tex, Japan); an example of the output data is shown in Fig. 1. The mean $R_{\mathrm{a}}$ of these peaks was calculated using the following equation:

$$
R_{\mathrm{a}}=(1 / N) \sum_{i=1}^{N}\left|z_{i}-z\right|
$$

where $N$ is the total pixel number, $z_{i}(\mu \mathrm{m})$ is the height of $i$, and $z(\mu \mathrm{m})$ is the mean height of $i$. Measurements were repeated at five points as for length of $300 \mu \mathrm{m}$ on the tablet surface and the mean value and standard deviation were plotted.

Tablet Strength Measurement A diametral tablet fracture test was performed at least $24 \mathrm{~h}$ after compression using a previously described method. ${ }^{10)}$ Tablet tensile strength, $S_{t}$, was calculated using the following equation $^{11)}$.

$$
S_{t}=2 H /(\pi D L)
$$

where $H(\mathrm{~kg})$ is hardness expressed as maximum load when the tablet fractured, and $D(\mathrm{~cm})$ and $L(\mathrm{~cm})$ are tablet diameter and thickness, respectively. $D$ and $L$ were measured with a digital-micrometer (DG-933, Ono Sokki Co. Ltd., Japan). The mean tensile strength was calculated from the measurements of 10 tablets.

Adhesive Force Measurement between Tablet Surface Particles and the Metal Plate Surface The adhesive force between tablet surface particles and the metal plate surface was measured using the equipment shown in Fig. 2. First, the tablet was attached to the upper surface of an aluminum plate (b) using double-sided adhesive tape (d). Next, the underside of the tablet was pressed against the surface of a metal plate (c) using constant weight (e.g., $200 \mathrm{~g}$ ) for $1 \mathrm{~min}$. The corresponding weight required on the other side of the balance (excluding the compression weight) to separate the tablet from the metal plate was taken as being equivalent to the adhesive force between the tablet surface particles and the metal plate surface.

\section{Results and Discussion}

Tablet sticking problems can occur when tablets are produced using a rotary tablet press. ${ }^{12)}$ Such sticking problems generally arise when the tablet press generates heat, especially if tablet compression requires a long time (i.e., the ad-

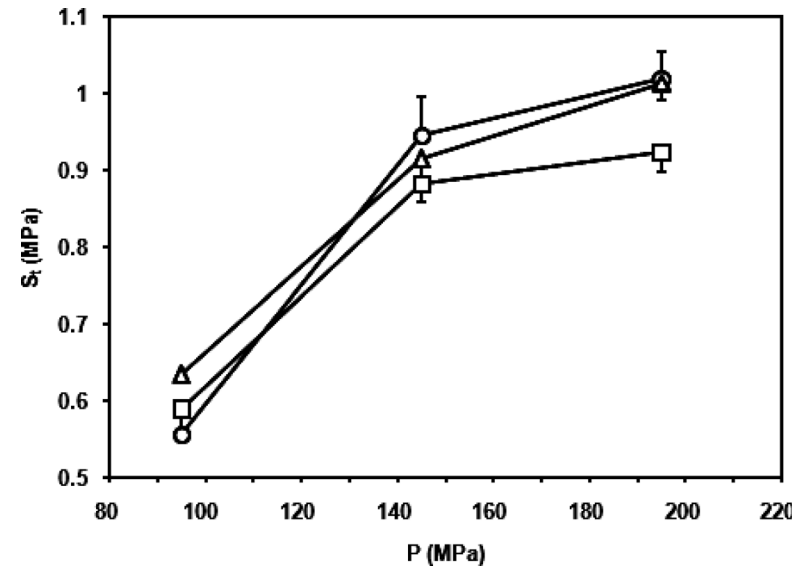

Fig. 3. Relationship between Compression Pressure (P) and Radial Tensile Strength $\left(S_{t}\right)$ at the Following Rotation Velocities (Binder Concentration Is $5 \%)$

$\bigcirc 10 \mathrm{rpm} ; \triangle 15 \mathrm{rpm} ; \square 20 \mathrm{rpm}$. The data are the mean \pm S.D., $n=10$.

hesive force between the punch plane and the tablet surface increases with an increase in the temperature of the tablet press). In the present study, the tablet adhesive force was assessed using butyl $p$-hydroxybenzoate, which has a low melting point of $68.4^{\circ} \mathrm{C}$; a condition commonly encountered during tablet production. The adhesive force in this case is high because measurement temperature/melting point $\left(T / T_{\mathrm{m}}\right)$ is high for low melting point materials, even at room temperature. ${ }^{13)}$

Effect of Compression Pressure on Tensile Strength Previously, the diametrical tensile strength was reported to be greatly affected by the water content of the tablet. ${ }^{1)}$ In this experiment, the effect of rotor rotation velocity and compression pressure force on tablet strength was examined. The tensile strength tended to increase with compression pressure for every rotor rotation velocity tested. In general, mechanical strength parameters, such as tablet hardness and friability, are affected by the internal structure of the tablet, which is determined by the composition and physical properties of each component in the tablet. ${ }^{12)}$ The relation between compression pressure and tablet strength for each rotation velocity is shown in Fig. 3. The experimental results indicated that tablet strength increased with compression pressure in a manner similar to that described previously. ${ }^{14,15)}$ Tablets produced at lower velocities were harder because the residence time under compression was longer.

Effect of Compression Pressure and Rotation Velocity on SCR The effect of compression pressure on sticking characteristics was examined. SCR corresponds ${ }^{9}$ to the shear force between the lower punch surface and the outer layer of the surface particles of the tablet. The change in SCR as a function of compression pressure is shown in Fig. 4. The figure shows that SCR tends to decrease slightly with an increase in compression pressure at each rotation velocity. As the rotational velocity of the rotor increases, the time required to achieve stress relaxation inside the tablet is inadequate. It is therefore assumed that the high residual pressure imparted to the lower punch, which is related to the adhesive force between the surfaces of the tablet and the lower punch, remains. Conversely, the SCR value decreases when the adhesive force between the tablet particles is greater than the adhesive 


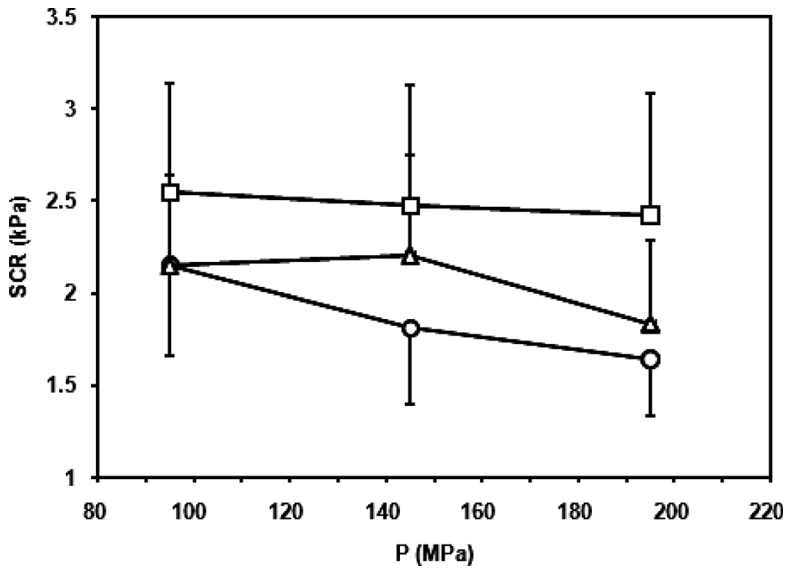

Fig. 4. Relationship between Compression Pressure (P) and Scraper Pressure (SCR) at the Following Rotation Velocities (Binder Concentration Is $5 \%)$

$\bigcirc 10 \mathrm{rpm} ; \triangle 15 \mathrm{rpm} ; \square 20 \mathrm{rpm}$. The data are the mean \pm S.D., $n=20$.

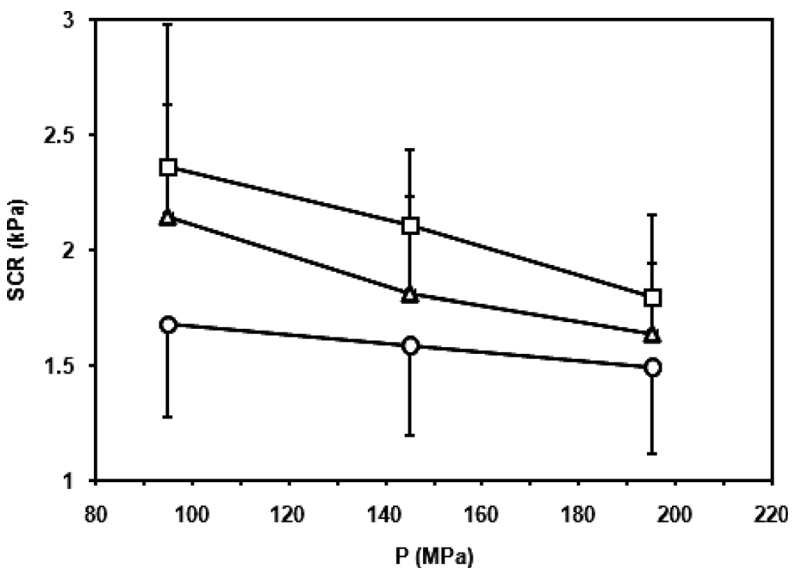

Fig. 5. Relationship between Compression Pressure (P) and Scraper Pressure (SCR) at the Following Binder Solution Concentrations (Rotation Velocity Is $10 \mathrm{rpm}$ )

3\% HPC; $\triangle 5 \%$ HPC; $\square 7 \%$ HPC. The data are the mean \pm S.D., $n=20$.

force between the particles and the punch interface.

In addition, as shown in Fig. 5, the SCR value also decreases with an increase in tableting pressure force at all binder concentrations.

The effect of rotation velocity on SCR when the binder concentration is fixed is shown in Fig. 6. The findings show that an increase in rotation velocity promotes sticking. Since pressure transmission is inadequate when the rotor velocity is high, as the rotation velocity increases, SCR also increases to values greater than the adhesive force between the tablet surface particles and lower punch surface, as shown in Fig. 6.

Adhesion Force between Tablet Surface Particles and the Metal Plate Surface To clarify the mechanism of adhesion, the adhesive force (F) between the tablet surface particles and the metal plate surface was measured using the equipment shown in Fig. 2. This experiment assumed that sticking occurs when the adhesive force (F) between the tablet surface particles and the metal plate surface is greater than the adhesive force between the tablet surface and the tablet interior particles. The results of the changes in the measured $\mathrm{F}$ obtained using tablets prepared with different tableting pressures are shown in Fig. 7. F showed a tendency

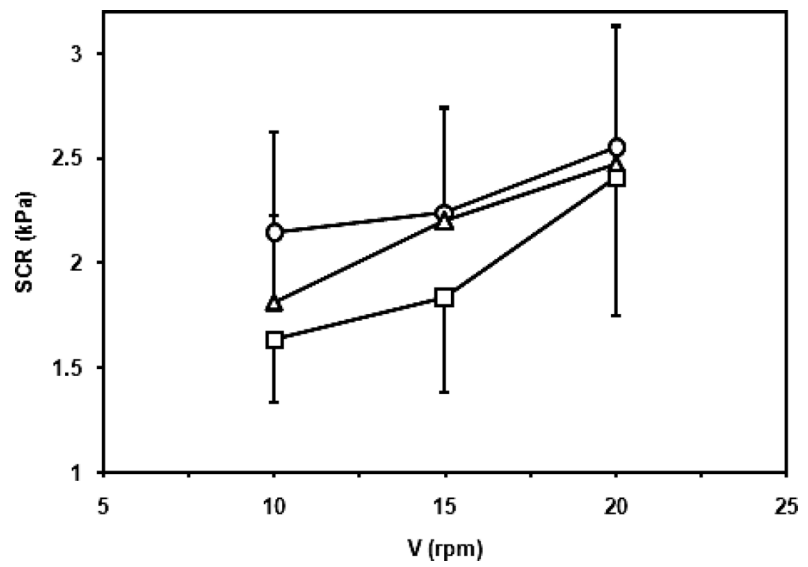

Fig. 6. Effect of Rotation Velocity (v) on Scraper Pressure (SCR) at the Following Compression Pressures (Binder Concentration Is 5\%)

$\bigcirc 98 \mathrm{MPa} ; \triangle 146 \mathrm{MPa} ; \square 195 \mathrm{MPa}$. The data are the mean \pm S.D., $n=20$.

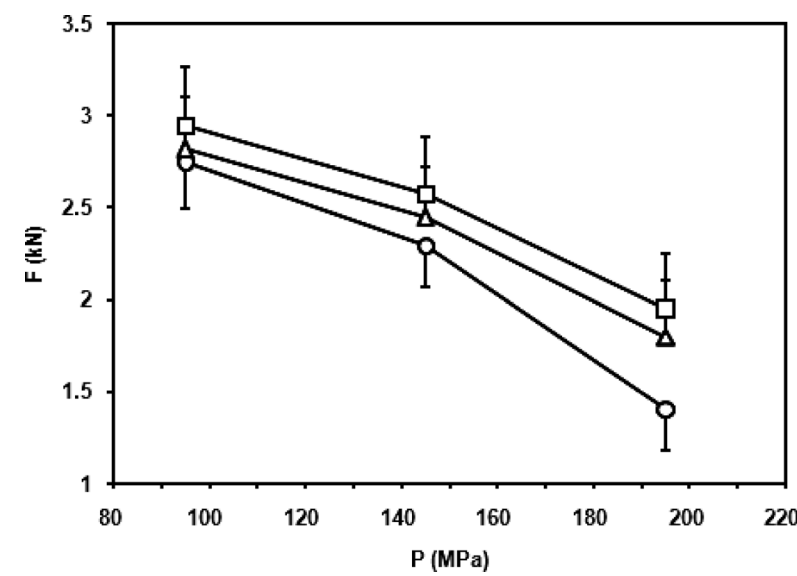

Fig. 7. Effect of Compression Pressure (P) on Adhesive Force (F) at the Following Rotation Velocities (Binder Concentration Is 5\%)

$\bigcirc 10 \mathrm{rpm} ; \triangle 15 \mathrm{rpm} ; \square 20 \mathrm{rpm}$. The data are the mean \pm S.D., $n=10$.

to decrease with an increase in tableting pressure, indicating that the adhesive force associated with an increase in tableting pressure is greater than the adhesive force between tablet surface particles and the lower punch surface.

The effect of binder concentration on adhesive force is shown in Fig. 8. F showed a tendency to increase with binder concentration. F decreased with an increase in tableting pressure, producing results similar to those shown in Fig. 5. Therefore, F shows a tendency similar to that of SCR (i.e., the SCR value also increases with an increase in adhesive force, as shown in Fig. 9). Although the relation between $\mathrm{F}$ and SCR showed some scatter $\left(R^{2}=0.443\right)$, a positive relationship was observed between F and SCR. However, the value of $\mathrm{R}^{2}$ decreased, and therefore, the deviation increased. It is regarded that $\mathrm{R}^{2}$ becomes small as there being in the increase of the deviation of SCR. Taken together, these results show that sticking occurs readily when tableting pressure is small, rotation velocity is rapid, and binder concentration is high.

Relation between SCR and Tablet Surface Roughness A previous study ${ }^{1)}$ reported that $R_{\mathrm{a}}$ was high when sticking occurred. Consequently, the tablet surface in this study was examined by scanning laser microscopy. The $R_{\mathrm{a}}$ values of the tablets were calculated using image processing software and 


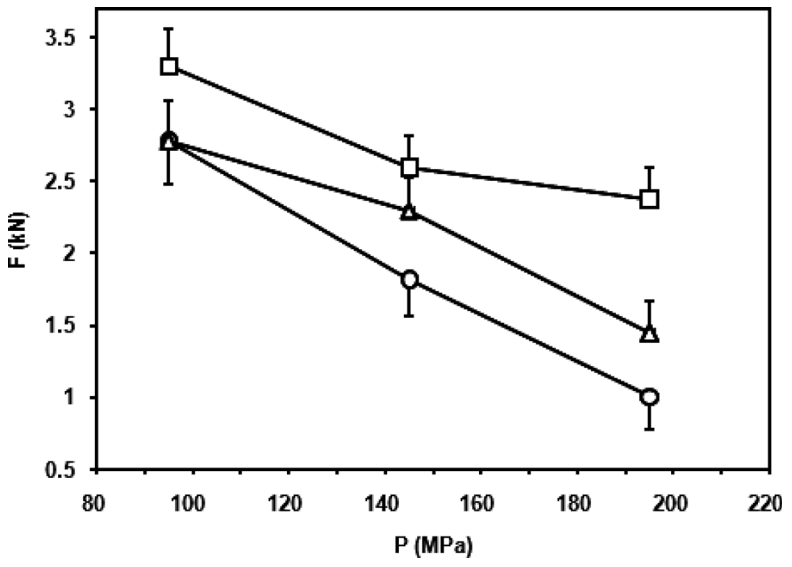

Fig. 8. Effect of Compression Pressure (P) on Adhesive Force (F) at the Following Binder Concentrations (Rotation Velocity Is $10 \mathrm{rpm}$ )

$\bigcirc 3 \% \mathrm{HPC} ; \triangle 5 \% \mathrm{HPC} ; \square 7 \% \mathrm{HPC}$. The data are the mean \pm S.D., $n=10$.

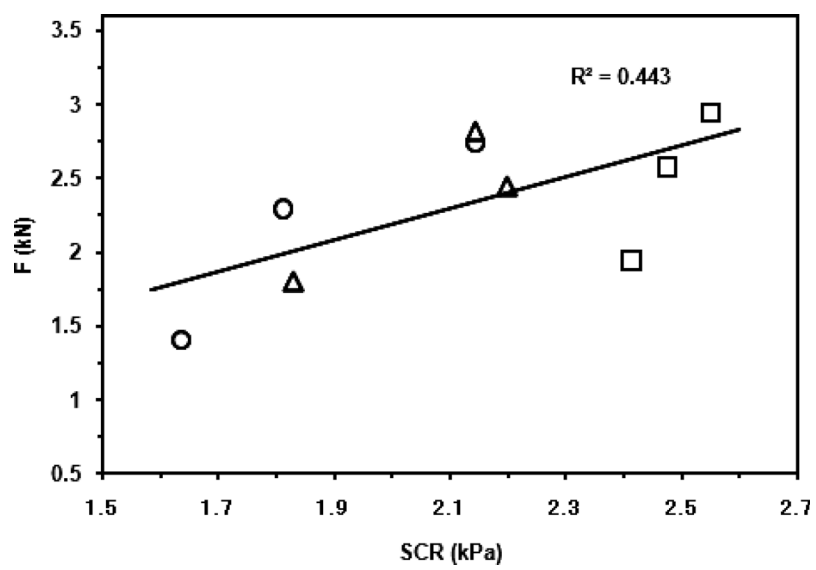

Fig. 9. Relationship between Scraper Pressure (SCR) and Adhesive Force (F) at the Following Rotation Velocities (Binder Concentration Is 5\%)

$\bigcirc 10 \mathrm{rpm} ; \triangle 15 \mathrm{rpm} ; \square 20 \mathrm{rpm}$.

Eq. 1. The relation between SCR and $R_{\mathrm{a}}$ of the tablets prepared using $5.0 \%$ binder granules is shown in Fig. 10. The relation between SCR and $R_{\mathrm{a}}$ was approximately linear; the $R_{\mathrm{a}}$ value was directly proportional to $\mathrm{SCR}\left(R^{2}=0.714\right)$. The $R_{\mathrm{a}}$ value appears to be a good indicator of sticking tendency, because sticking was frequent when $R_{\mathrm{a}}$ was large.

\section{Conclusion}

Scraping pressure decreases as tableting pressure increases, and increases with compression velocity and binder concentration. As a consequence, the shear force between the tablet surface and the lower punch surface can be assumed to

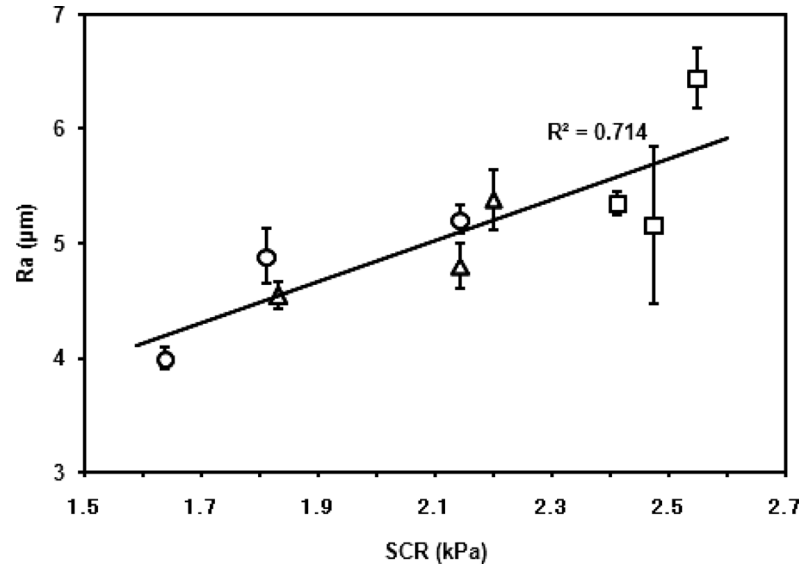

Fig. 10. Relationship between Scraper Pressure (SCR) and Tablet Surface Roughness $\left(R_{\mathrm{a}}\right)$ at the Following Rotation Velocities (Binder Concentration Is $5 \%$ )

$10 \mathrm{rpm} ; \triangle 15 \mathrm{rpm} ; \square 20 \mathrm{rpm}$. The data are the mean \pm S.D., $n=25$.

decrease as tableting pressure increases.

In addition, the adhesive force between tablet surface particles and the metal plate surface increases when the tableting rotation velocity and binder concentration are high. Therefore, the adhesive force between the surface of the tablets and the metal plate surface increases with binder concentration. Further, SCR increased when it was positively correlated with $R_{\mathrm{a}}$.

\section{References}

1) Danjo K., Kojima S., Chen Y.-C., Sunada H., Otsuka A., Chem. Pharm. Bull., 45, 706-709 (1997).

2) Schmidt Von P. C., Stefens K. J., Kneble G., Pharm. Ind., 45, 800 805 (1983).

3) Naito S., Nakamichi K., Chem. Pharm. Bull., 17, 2507-2514 (1969).

4) Naito S., Shimizu I., Iwaki S., Chem. Pharm. Bull., 19, 1949-1956 (1971).

5) Naito S., Masui K., Shiraki T., J. Pharm. Sci., 66, 254-259 (1977).

6) Toyoshima K., Yasumura M., Onishi N., Ueda Y., Int. J. Pharm., 46, $211-215$ (1988).

7) Sugimori K., Mori S., Powder Technol., 58, 259-264 (1989)

8) Sawaguchi K., Uemura T., Mizushima Y., Pharm. Tech. Jpn., 24, 1577 -1580 (2009)

9) Danjo K., Kamiya K., Otsuka A., Chem. Pharm. Bull., 41, 14231427 (1993).

10) Danjo K., Otsuka A., Chem. Pharm. Bull., 36, 763-768 (1988).

11) Akazawa T., Doboku Gakkaishi, 28, 777-787 (1943).

12) Aoki S., Danjo K., Yakugaku Zasshi, 118, 511-518 (1998).

13) Danjo K., Otsuka A., Yakugaku Zasshi, 100, 893-899 (1980).

14) Goto K., Sunada H., Danjo K., Yonezawa Y., Drug Develop. Ind. Pharm., 25, 869-878 (1999).

15) Danjo K., Kozaki K., Sunada S., Otsuka A., Chem. Pharm. Bull., 42, $2121-2125$ (1994) 